\title{
Constituição de masculinidades juvenis em contextos "difíceis": \\ vivências de jovens de periferia na França*
}

\author{
José Geraldo Soares Damico** \\ Dagmar E. Estermann Meyer ${ }^{* * *}$
}

\begin{abstract}
Resumo
Apoiados nos estudos de gênero e culturais pós-estruturalistas e na antropologia política, analisamos informações geradas em discussões de grupo e entrevistas com jovens franceses de Grigny Centre - periferia de Paris - para discutir elementos, enunciados em formato de "palavras significativas", implicados com processos $\mathrm{de}$ constituição de identidades masculinas juvenis naquele contexto. Argumentamos que essas palavras significativas dimensionam modos de ser $e$ de viver e de exercitar a masculinidade. A discussão pode contribuir para pensar a "problemática" da juventude urbana pobre brasileira.
\end{abstract}

Palavras-chave: Juventude, Masculinidade, Identidade, Periferias Urbanas.

\footnotetext{
* Recebido para publicação em março de 2010, aceito em maio de 2010.

${ }^{*}$ Mestre e doutorando em Educação (PPGEDU/FACED/UFRGS); professor adjunto ULBRA/RS. zdamico@yahoo.com.br

${ }^{* * *}$ Doutora em Educação pela UFRGS. Prof ${ }^{a}$ Associada na Faculdade de Educação da UFRGS. Membro do Grupo de Estudos de Educação e Relações de Gênero (GEERGE). Bolsista de Produtividade em Pesquisa do CNPq. dagmaremeyer@yahoo.com.br
}

cadernos pagu (34), janeiro-junho de 2010:143-178. 
Vivências de jovens de periferia na França

Constitution of Juvenile Masculinities in "Difficult" Contexts: Experiences of Youths in Urban Outskirts in France

\begin{abstract}
Relying on gender studies and post-structuralist cultural and political anthropology, we analyze information generated in group discussions and interviews with French youngsters from Grigny Center - on the outskirts of Paris- with a view to discussing elements, appearing in the discourse as "relevant" words, involved in the processes of constituting juvenile male identity in that particular context. We suggest that these relevant words define ways of being and living and of putting into practice masculinity. This discussion may assist in reflecting on the 'problem' of poor urban youth in Brazil.
\end{abstract}

Key Words: Youth, Masculinity, Identity, Urban Outskirts. 
José Geraldo Damico e Dagmar Meyer

\section{O texto em contexto e sua promessa}

Hoje fui a Grigny pela primeira vez. Tomo o RER ${ }^{1}$ na Gare de Lyon para uma viagem que leva cerca de quarenta minutos. Ao longo do caminho o trem passa por vários subúrbios. Pela janela vejo alguns prédios com mais de 10 andares, edifícios degradados e outros parecendo pouco habitados, muitos jardins e pequenos bangalôs. Vejo, também, uma grande área industrial, com muitas fábricas que parecem desativadas. Grigny situa-se numa espécie de morro e quando o trem se aproxima, de baixo para cima, vejo uma impressionante imagem diante de mim. Do lado esquerdo do trem, na encosta do morro, encontra-se um pequeno, simpático e típico subúrbio francês, como muitos outros que tenho visto por aqui. Do lado direito vejo um conjunto de edifícios atrás de um muro enorme, no topo de uma colina. Quando chego à estação tenho que subir uma escada muito alta para chegar à saída e outra para chegar até a rua... (Diário de campo, 03/05/2009).

Em minha segunda visita, chego mais cedo do que o combinado com $\mathrm{Amar}^{2}$ para conhecer um pouco de Grigny II. A maioria dos prédios tem em torno de onze andares, com antenas parabólicas presas às paredes e cordas nas varandas onde se penduram todos os tipos de coisas. Eles correspondem muito bem às imagens que tenho visto dos subúrbios parisienses na mídia. Para minha surpresa, quando saio da estação $e$ olho para a direita em direção a Grigny II, vejo pelo menos 10 veículos grandes da polícia francesa, muitos policiais perfilados e bem armados, com equipamentos de proteção (ombreiras, joelheiras, cotoveleiras pretas) - um vestuário que, até agora, só tinha visto em filmes de ficção. Ao mesmo tempo, pessoas

1 Rede Expressa de Paris é o trem urbano que liga Paris aos subúrbios em todas as direções. O estado de conservação, a superlotação, a demora e as freqüentes greves ou problemas nas linhas são fontes constantes de descontentamento da população.

2 Amar Henni é doutorando de antropologia política da Universidade Paris 8. 
Vivências de jovens de periferia na França

caminhavam tranquilamente, sozinhas ou em grupos, às vezes compostos por famílias numerosas com vários carrinhos para bebês. Não agüentei e perguntei para um garoto de 12 anos se tinha acontecido alguma coisa que justificasse a presença de tantos policiais e ele me respondeu com muita tranquilidade que não, que aquilo era normal (Diário de campo, 07/05/2009). ${ }^{3}$

A cidade de Grigny se divide em dois grandes conjuntos: Grande Borne e Grigny 2. Há 50 anos, Grigny era apenas uma pequena vila, composta por casas agrupadas em torno de duas grandes fazendas. Os habitantes costumavam criar animais $e$ plantar batatas até o período da grande industrialização da região, que trouxe novas possibilidades de trabalho e de geração de renda, além de crescimento econômico e desenvolvimento, num contexto em que o incentivo à imigração contribuía para aumentar as chances do país concorrer, em igualdade de condições, com as outras nações européias.

Os primeiros imigrantes que ali se instalaram, no início do século XX, eram diaristas italianos que vieram para trabalhar nas escavações de dois grandes lagos, perto do vilarejo que se transformou na atual Grigny. Esses dois lagos, que existem até hoje, desempenharam um papel importante na campanha de marketing para o residencial Grigny II, erguido junto à estação de trem dos dias atuais, pois promoviam a área como um lugar aprazível para se viver (Giblin, 2009).

Os primeiros movimentos de transformação do vilarejo começaram em meados da década de 1950. Foi construída uma estrada ao lado da vila que, atualmente, divide o espaço de

3 Excertos extraídos de diário de campo escrito por José Soares Damico, entre abril de 2009 e janeiro de 2010, em trabalho de campo que integrou o plano de atividades do estágio de doutorado sanduíche na Universidade Paris 8 (com bolsa da CAPES), e que foi realizado em um dos subúrbios de Paris, considerado um dos mais violentos da França. As informações geradas nesse trabalho de campo fazem parte de sua pesquisa de doutorado, em andamento, cujo tema é "Lazer(es), juventude(s) e violência(s): articulações em torno do biopoder". 
Grigny em duas partes: de um lado se encontra Grigny II, do outro lado está outro grande, e agora degradado, residencial: Grand Borne. Ao longo da rodovia novas fábricas, dentre elas uma da coca-cola, foram construídas e, nelas, a população da área encontrava trabalho. Grigny II e a Grand Borne (criadas na década de 1960) resultaram de uma política governamental para a construção de novos bairros nos arredores de Paris (Wacquant, 2008). Tal política foi motivada pela escassez de moradias $e$ porque estes imigrantes estavam vivendo em favelas.

A construção destes bairros levou a um rápido crescimento populacional em Grigny que, em 1968, contava com 2.957 habitantes e em 1972 já tinha 21.655. Esse aumento acelerado, em apenas quatro anos, acentuou os problemas de infra-estrutura, de educação, de saúde e de trabalho que persistem até os dias de hoje.

Atualmente, o território que foi concebido para ser um bairro tranqüilo e moderno é representado como uma das zonas mais pobres e mais difíceis dos subúrbios de Paris. Segundo a mídia, o Estado francês e grande parte dos trabalhos acadêmicos que se ocupam de problemáticas que envolvem violência, migração e exclusão social, é um dos mais explosivos subúrbios franceses. A população apresenta muitas dificuldades socioeconômicas. A área tem cerca de 25.000 habitantes registrados, mas o número efetivo deve passar de 30.000 (conforme boletim da prefeitura), uma vez que há um grande número de pessoas sem documentos, que não responde aos recenseadores por medo das ameaças de expulsão do governo francês. A maioria dos habitantes acima dos 40 anos veio da região de Magreb $^{4}$ ou da África sub-saariana. ${ }^{5}$ Os mais jovens são, na sua maioria, nascidos na França.

\footnotetext{
4 Argélia, Tunísia, Líbia, Mauritânia e Marrocos.

5 A cidade, segundo os próprios moradores, está dividida entre a população de origem africana, que vive na Grand Borne, e a população de origem árabe, que vive em Grigny 2.
} 
Vivências de jovens de periferia na França

Além das habitações degradadas, em boa parte dos prédios os elevadores não funcionam, e são comuns casos de famílias com mais de dez crianças que vivem em um apartamento de três quartos. A cidade tem uma das maiores taxas de desemprego de toda a França, chegando a quase 50\% para jovens entre 15 e 24 anos. Para a população geral essa taxa é de 30\% (Kokoreff, 2003).

São, justamente, características como forte densidade populacional, concentração de população estrangeira, grande proporção de jovens com menos de 30 anos, taxas de desemprego maiores do que a média nacional, altos índices de fracasso $e$ evasão escolares, bem como a perceptível tensão entre diferentes grupos sociais, que são utilizadas para nomear subúrbios parisienses como esse de subúrbios sensíveis, desfavorecidos, difíceis e violentos. $\mathrm{O}$ uso de tal terminologia não é fortuito $e$ produz determinados efeitos classificatórios, que também variam segundo as circunstâncias, contextos e meios em que são empregados - políticas públicas, noticiários, estudos acadêmicos, pautas de políticos de diferentes partidos e/ou de grupos $e$ movimentos sociais. Nesse sentido, pode-se dizer que existe uma rede de instituições e de atores sociais (políticos eleitos, responsáveis por associações, educadores, pesquisadores e profissionais da mídia, por exemplo) implicada com a produção de um conjunto de representações sobre a população que reside nesses territórios, com destaque para a população jovem que, no limite, opera tanto na direção de uma criminalização quanto de uma vitimização à priori.

Evidentemente que não se trata, aqui, de avaliar a veracidade e correção de notícias e/ou imagens veiculadas pela mídia, nas análises e resultados de trabalhos acadêmicos, na posição externada por políticos, educadores e agentes de segurança, assim como nos textos programáticos das políticas que pretendem dar conta do que é nomeado e passa a ser abordado como problema social, no sentido de dizer que elas são falsas ou verdadeiras; ou, ainda, de dizer que elas desencadeiam os comportamentos considerados inadequados (e/ou ameaçadores 
da ordem instituída) dos jovens moradores dos subúrbios. Trata-se de considerar, seguindo Foucault (1987), que os discursos e as práticas a eles vinculadas, quando descrevem e nomeiam indivíduos, grupos, fatos e processos sociais, constroem um saber sobre eles e, portanto, implicam-se com sua produção num determinado sentido e direção. Ou seja, as palavras estão implicadas com a produção das coisas que elas nomeiam $e$ tornam inteligíveis num determinado tempo, contexto $e$ linguagem, $e$ isso inclui a criminalização, a vitimização, a discriminação e a desigualdade social e cultural que, de forma articulada ou alternada, passam a ser "coladas" a essas populações e passam a distingui-las e a identificá-las como tal.

Assim, entendemos que as descrições de Grigny como um território problemático, especialmente no que concerne a seus jovens habitantes, têm efeitos que dimensionam formas de ser $e$ de viver nesse lugar e produzem modos de ser jovem e exercitar determinadas formas de masculinidade e feminilidade, que é o que nos interessa abordar, aqui. Entendemos, também, que a discussão sobre a constituição dessas identidades masculinas, nesse lugar-tempo específicos, pode contribuir para a reflexão acerca de intervenções educativas propostas para dar conta da "problemática" da juventude urbana, com ênfase na juventude das periferias urbanas, no Brasil. Dentre outros aspectos, porque não podemos esquecer que grande parte das iniciativas de intervenção, também no Brasil, é apoiada ou financiada por organismos globais $e$ se sustenta em pressupostos homogêneos $e$ universais que acabam produzindo uma certa naturalização de representações que articulam juventude, masculinidade e pobreza com violência e criminalidade. ${ }^{6}$

${ }^{6}$ Essa afirmação se sustenta, dentre outras, em pesquisas como a de José Damico e Sandra dos Santos Andrade. A primeira, em andamento no Município de Canoas/RS, Região Metropolitana de Porto Alegre, entre 2008 e 2009, problematiza políticas públicas voltadas à juventude pobre que, ao proporem programas e projetos na área de educação, saúde e esporte, ao mesmo tempo, representam estes jovens como problema de segurança pública. A segunda 
Vivências de jovens de periferia na França

Todo texto acadêmico delineia um tema, o trajeto argumentativo de sua enunciação e, também, uma (ou mais de uma) promessa. Assim, e tendo em vista o contexto descrito e a potência reflexiva que nele vislumbramos, trabalhamos, aqui, com falas de jovens que ali cresceram e vivem, para discutir elementos que, desde sua própria capacidade de formulação, e de forma articulada, estão implicados com a produção de identidades juvenis masculinas de determinado tipo. A abordagem teóricometodológica utilizada constrói-se na interface dos estudos de gênero, dos estudos culturais e da antropologia política, em especial de estudos e de autores/as que têm proposto uma aproximação crítica com a teorização foucaultiana. Torna-se importante explicitar, então, que mesmo reconhecendo a estreita imbricação de temas como a problemática da migração em contextos europeus (sobretudo quando ela envolve populações muçulmanas), ou a proposição e avaliação de políticas $e$ programas de intervenção estrito senso, com o recorte temático que estamos propondo, não é disso que vamos tratar. De forma muito mais modesta - eis nossa promessa - pretendemos discutir um conjunto de elementos, enunciados em reuniões de grupo com os jovens, em formato de "palavras significativas", que estão implicados com processos de constituição de identidades juvenis nesses contextos.

(Andrade, 2008) discute a educação de jovens e adultos (EJA) e alguns dos efeitos de sua juvenilização sobre os processos de construção de identidades juvenis na periferia de Porto Alegre. Os dois estudos foram orientados por Dagmar E. E. Meyer. 
José Geraldo Damico e Dagmar Meyer

\section{“A violência dos jovens não cessa de aumentar e nós precisamos endurecer" 7 - modos de ver e modos de fazer}

A frase acima, pronunciada por uma ministra francesa em 2007, poderia ser reconhecida como uma formulação de algumas autoridades brasileiras envolvidas com segurança pública. Entretanto, como vivemos em tempos e contextos caracterizados como de mudança ou, ainda, como pós-modernos, póscapitalistas, líquidos, globalizados etc., e que nos confrontam com crises sociais profundas e complexas, poderia ser útil experimentar outros olhares e formas de apreensão, descrição e interpretação da multiplicidade de sujeitos e de grupos que se enredam nesses "cenários" contemporâneos. Michel Foucault chama atenção para o fato de

que não há exercício do poder sem uma certa economia dos discursos de verdade que funcionam nesse poder, a partir e através dele. Somos submetidos à produção da verdade e só podemos exercer o poder mediante a produção da verdade (Foucault, 2006:28-29).

Assim, pode-se dizer que boa parte dos estudos sobre juventudes e sobre periferias urbanas, mesmo aqueles que assumem posições comprometidas com maior equidade e justiça social, acaba se apoiando num conjunto de pressupostos científica e politicamente legitimados, que definem a juventude como "um problema" a ser enfrentado. ${ }^{8}$ De forma intencional ou não, essa "economia de discursos" tem contribuído, dentre outras coisas, para naturalizar a relação entre criminalidade, violência e pobreza nas periferias urbanas $e$, nesse processo de naturalização, jovens do sexo masculino tem sido, usualmente, representados como

7 Afirmação de Rachida Dati, ministra do Interior na França, em 2007 (Muchielli, 2008:23). O Ministério do Interior na França corresponde, no Brasil, ao Ministério da Justiça.

8 cf., por exemplo, revisões sobre o tema de Spósito (1997 e 2002). 
Vivências de jovens de periferia na França

perigosos e/ou como vítimas. A força desses discursos age no sentido de nos "fazer ver" tanto as periferias das cidades quanto a juventude que os habita como se fossem homogêneas, com uma visão que oblitera (tanto dentro, quanto entre) suas especificidades constitutivas.

O problema da juventude - com ênfase especial na juventude que vive em periferias urbanas -, quando colocado na perspectiva da criminalização ou da vitimização, é uma construção discursiva (científica, midiática e política). Essa afirmação não implica deixar de reconhecer que existem comportamentos $e$ situações violentas cujos autores são jovens, e que estes podem ser mais ou menos numerosos segundo os diferentes momentos e territórios. Estamos apenas dizendo que, qualquer que seja o modo como eventos relacionados a esses grupos se desenvolvam, eles - sobretudo os jovens homens - são representados e/ou assumidos como problemáticos nos discursos públicos, que posicionam determinados sujeitos, de determinados extratos sociais e de determinados territórios, como ameaças (e/ou como vítimas) potenciais à ordem instituída.

Muitos desses discursos sugerem o endurecimento de penas prisionais e a redução da maioridade penal e são tão potentes que é difícil argumentar na contramão da contundência e assertividade com que estatísticas e fatos deles derivados são apresentados. No caso da França, esse debate está muito acirrado, em decorrência dos confrontos entre a polícia e jovens, em novembro de $2005 .{ }^{9}$ Entre as respostas do poder público francês a eles destaca-se a do

9 Apesar dos confrontos entre a polícia e jovens das periferias terem começado, na França, em meados da década de 1990 e continuarem ocorrendo, os distúrbios que começaram em Clichy-sous-Bois, em novembro de 2005, em função da morte de dois jovens pela polícia, se espalharam por praticamente toda a França e ganharam destaques na mídia internacional: foram centenas de carros queimados, saques e milhares de prisões. Esse acontecimento é considerado um marco fundamental nas relações entre o Estado francês e a juventude periférica; ao mesmo tempo, foi um trunfo importante para a eleição do presidente Nikolas Sarkozy que, com declarações como essa, construiu uma imagem de político forte que não cede jamais. 
Ministro do Interior na época (o atual presidente Nicolas Sarkozy), para quem esses jovens constituem a "escória" que ele se comprometia a "limpar" (Giblin, 2009:163). Em 2007, foi criada uma polícia especial para os subúrbios e os Ministérios da Educação e do Interior anunciaram uma nova reforma na lei do código penal de menores. Em 2009, um novo grupo móvel da polícia foi colocado em ação para atuar em escolas qualificadas como problemáticas.

Entretanto, quando questionamos, por exemplo, sobre o que tem sido apresentado como elementos desencadeadores da, ou que explicam a, violência juvenil, encontramos na mídia $e$ em boa parte da literatura biopsicológica termos e pressupostos como: adolescência como fase naturalmente problemática em função de intensas transformações físicas e psíquicas; famílias desestruturadas; falta de limites; distúrbios afetivos e emocionais; uso de drogas; incitação ao consumo; falta de projetos de vida; fracasso e evasão escolar; desenraizamento cultural; maior tendência de homens para o envolvimento com atos violentos em função de sua constituição biológica (notadamente, da ação da testosterona) ou de seu pertencimento religioso, étnico, etc. Ou seja, noções que instituem esses e outros atos como traços de individualidade. José Machado Pais pondera:

Freqüentemente, dos "atos" passa-se às "maneiras de ser" e estas são mostradas como não sendo outra coisa que os próprios atos de violência. Implicitamente, surge $\mathrm{o}$ reconhecimento de que um ato de violência cometido por um jovem negro ou cigano resulta da maneira de ser das suas etnias de pertença. Nesse julgamento, o que se pune não é o ato de violência em si, mas a imagem preconcebida do jovem delinqüente: ou porque usa brinco na orelha, ou porque tem um corte de cabelo exótico, ou porque exibe uma tatuagem, ou pela simples cor da pele (Pais, 2008:14).

Assim, muitas das políticas e programas direcionados à juventude, tanto na França quanto no contexto brasileiro, acabam 
Vivências de jovens de periferia na França

por assumir e reiterar uma equação que relaciona determinados problemas (como violência, infrações diversas, uso abusivo de álcool e substâncias psicoativas, etc.) a uma essência que, de certa forma, "aprisiona" e reduz a composição complexa $e$ multifacetada de identidades juvenis masculinas de periferias urbanas. Ao operar dessa forma funcionam, estrategicamente, como modalidades de governo de determinadas práticas sociais, no sentido que lhes é dado por Foucault, e que envolvem "não apenas as estruturas políticas e a gestão dos Estados, mas a maneira de dirigir a conduta dos indivíduos ou dos grupos" (Foucault, 1999:244).

Neste texto, assumimos que tensões sociais, sejam elas quais forem, se resolvem de formas historicamente específicas $e$ necessitam ser analisadas nas suas incorporações políticas particulares e não como escolhas morais unívocas. Assim, em um contexto em que a juventude e, dentro dela, a juventude masculina, tem sido posicionada, de forma múltipla, como potência e, sobretudo, como problema social relevante - seja pelos problemas com que nos confronta, seja por suas potencialidades presentes e futuras - se torna interessante $e$ necessário refletir sobre os desafios que se alinham em torno desta problemática nas periferias urbanas.

No âmbito do referencial teórico-metodológico em que nos apoiamos, cinco pressupostos ${ }^{10}$ constituem o que chamamos, no subtítulo, de nossos modos de ver nesta análise:

- Um primeiro, que permite conceber cultura como um campo de luta e contestação em que se produzem tanto os sentidos quanto os sujeitos que constituem os diferentes grupos sociais em sua singularidade (cf. Silva, 1999; Giles e Midletton, 1999);

${ }^{10}$ Essa abordagem teórica, e os conceitos que dela se desdobram, tem sido extensamente discutida em estudos do campo da educação brasileira contemporânea, de modo que vamos apresentá-los apenas em forma de pressupostos, buscando operar com e dentro dela ao longo de nossa argumentação. 
- Um segundo, que defende a centralidade da linguagem (em sentido amplo) nos processos de significação do mundo em que vivemos, para tratá-la como lócus de produção das relações que a cultura estabelece entre sujeito, conhecimento e poder (cf. Hall, 1997);

- Um terceiro, que entende educação como conjunto de processos pelos quais indivíduos são transformados, ou se transformam, em sujeitos de uma cultura. E tornar-se sujeito de uma cultura envolve um complexo de forças e de processos de aprendizagem que, nas sociedades contemporâneas, envolvem a família e a escola, mas vão muito além, incluindo, por exemplo, a mídia, os grupos de iguais e políticas e programas sociais (cf. Shore e Wright, 1997; Meyer, 2005);

- Um quarto supõe considerar que representação engloba práticas de significação lingüística e cultural e sistemas simbólicos através dos quais os significados são construídos. Os sistemas de representação, ao construírem lugares que nos posicionam ou, ao proporcionarem respostas que nos possibilitam entender aquilo que somos, constroem posições de sujeito, produzem identidades. Silva (1999:46) afirma que
a identidade cultural ou social é o conjunto daquelas características pelas quais os grupos sociais se definem como grupos: aquilo que eles são. Aquilo que eles são, entretanto, é inseparável daquilo que eles não são, daquelas características que os fazem diferentes de outros grupos.

Nesse sentido, processos de produção lingüística de identidades e diferenças, bem como processos de produção cultural e social de identidades e diferenças, estão estreitamente relacionados; e esta produção se dá, em grande parte, nos (e através dos) sistemas de representação social. Os sistemas de representação, em conexão com o poder que opera na linguagem, estão envolvidos, de forma fundamental, com aquilo que nos tornamos; 
Vivências de jovens de periferia na França

- Um quinto, que permite argumentar que gênero funciona como um organizador do social e da cultura e, nessa perspectiva, engloba todos os processos pelos quais a cultura constrói $e$ distingue corpos e sujeitos femininos e masculinos. Dentre outras coisas, isso se operacionaliza pela articulação de gênero com outras "marcas" sociais, por exemplo, classe e raça/etnia, e cada uma dessas articulações produz modificações importantes nas formas pelas quais feminilidades e masculinidades são, ou podem ser, vividas e experenciadas por grupos diversos, dentro dos mesmos grupos ou, ainda, pelos mesmos indivíduos, em diferentes momentos de sua vida (cf. Nicholson, 2000; Louro, 2005; Meyer, 2004).

Nossos modos de ver conectam-se, intimamente, aos modos de fazer, ou seja, aos procedimentos de investigação utilizados no trabalho de campo durante o qual o material empírico, aqui analisado, foi produzido. O trabalho de campo foi realizado entre março de 2009 e janeiro de 2010, utilizando a estratégia de reuniões, com a proposição de discussões em grupo, uma vez por semana $^{11}$, com cerca de 10 jovens moradores, entre 17 e 30 anos. A maioria do grupo foi composta por homens jovens, mas pelo menos três mulheres também estiveram presentes. A composição do grupo nem sempre foi a mesma; ela se alterava quando alguém trazia um amigo ou amiga para conhecer o trabalho, ou quando alguém que tinha faltado à reunião anterior voltava na reunião seguinte.

Os componentes do grupo foram selecionados e convidados por Amar Henni ${ }^{12}$ que, por conhecer muito bem as famílias que vivem em Grigny, pode operacionalizar a heterogeneidade

${ }^{11}$ Não fizemos reuniões em alguns períodos, como nas férias de verão em julho, quando a maioria dos/das jovens viajava para visitar familiares que ficaram nos países de origem de seus familiares, e durante o Ramadan, em setembro, quando a cidade praticamente pára por conta das obrigações religiosas.

${ }^{12}$ Amar Henni é estudante de doutorado sob a supervisão de Sylvain Lazarus (Professor da Universidade de Paris 8) e ex-diretor do serviço de juventude em Grigny. 
prevista no desenho metodológico prévio. O fato do convite para participar ter partido de Amar também criou, desde o início, um clima de confiança e liberdade de expressão que dificilmente teria se instaurado em outras circunstâncias. Com exceção de duas meninas da área vizinha (Ris Orangis ${ }^{13}$ ), os outros jovens viviam em Grigny, na Grande Borne e em Grigny II. Todos tinham origens imigrantes - Senegal, Mali, Argélia, Marrocos e Tunísia - a maioria estava estudando ou procurando um emprego ou um estágio. Dois deles já tinham passado pela prisão.

Inspirados pelos estudos que trabalham com a metodologia que Sylvain Lazarus ${ }^{14}$, na primeira reunião do grupo pedimos aos jovens para citar o que chamamos de palavras significativas, ou seja, palavras que são importantes para entender e descrever suas vidas e como eles se vêem. Em cada uma das reuniões seguintes discutiu-se o significado e o valor atribuído a algumas dessas palavras. $\mathrm{Na}$ seqüência da reunião essas palavras foram agrupadas em categorias que os jovens definiram como "nós" $e$ "eles", e são esses dois agrupamentos - constitutivos dos processos de diferenciação cultural, que resultam em produção de identidades e de diferenças - que utilizamos em nossa análise, neste artigo. ${ }^{15}$

Os textos gerados pelo trabalho de campo são analisados, aqui, na perspectiva da análise cultural ancorada na teorização foucaultiana (cf. Fischer, 2001; Meyer et alii, 2006) para descrever e problematizar discursos (Foucault, 1987) que, imbricados, permitem

${ }^{13}$ Ris Orangis se localiza ao lado de Grigny e ambas fazem parte do departamento de Essone, da região da Île de France.

${ }^{14}$ Desenvolvida no livro Anthropologie du Nom [Antropologia do Nome], 1996.

${ }^{15}$ Três pesquisadores (Amar Henni, Sylvain Lazarus e José Damico) participaram do grupo de discussão e, individualmente, fizeram anotações de cada reunião que constituíram um diário de campo; as anotações de cada reunião eram revistas e discutidas entre os três $e$, a partir dessa discussão, organizava-se a reunião seguinte. Essas anotações também serviram como ponto de partida para algumas entrevistas individuais que se julgou necessário fazer nos últimos dois meses de convivência com os jovens 
Vivências de jovens de periferia na França

aos jovens expressar-se de um determinado modo e não de outros. Nessa direção, Beatriz Fischer (1997:17) assinala que "nos discursos, existe um lugar determinado e vazio que pode ser ocupado por diferentes indivíduos", e pode-se considerar que é desses lugares que indivíduos se tornam capazes de pensar, falar e agir, de determinados modos, em circunstâncias específicas. Com a análise cultural buscamos, então, re-conhecer e descrever algumas posições de sujeito que os jovens ocupam quando falam de si e de suas vidas, das relações que estabelecem entre si e com as instituições sociais e políticas com as quais interagem, bem como com as ações educativas que nelas vivenciam. Buscamos, sobretudo, compreender como esses discursos são atravessados $e$ reconfigurados pelo gênero, e também as formas apontadas como "adequadas para viver" como jovem e como homem que tais discursos instituem, para colocá-las em relação com significados $e$ práticas compartilhados nesses grupos sociais.

\section{Nós e Eles: pólos interdependentes e constitutivos de identidades masculinas juvenis}

Com relação a Nós, as palavras significativas enunciadas na primeira reunião de grupo foram: coragem, respeito, família, lealdade, medo, traição, confiança, reputação, honra, orgulho $e$ dinheiro, enquanto que a Eles foram associadas palavras como polícia, in-justiça, mídia, desemprego, escola, política. Em função do tema e do critério que define a extensão do artigo escolhemos significações que se desdobram, ou se erigem em torno, das palavras família, honra e reputação para discutir o "nós" $e$, injustiça, polícia e mídia para discutir o "eles".

Nós, como argumenta Bauman (2001:202), significa "pessoas como nós", enquanto que eles significa "pessoas que são diferentes de nós". Mas, segue o autor, desenvolvendo uma argumentação aparentemente óbvia e, ao mesmo tempo, profundamente esclarecedora: 
José Geraldo Damico e Dagmar Meyer

Não que nós sejamos idênticos em tudo; há diferenças entre nós, ao lado das características comuns, mas as semelhanças diminuem (...) e neutralizam seu impacto. $\mathrm{O}$ aspecto em que somos semelhantes é decididamente mais significativo do que o que nos separa. (...) E não que eles sejam diferentes de nós em tudo; mas eles diferem em um [ou mais de um] aspecto que é (...) importante o bastante para impedir uma posição comum e tornar improvável a solidariedade, independente das semelhanças que existam. É uma situação tipicamente ou/ou...

Essa atribuição de significados tem a ver com processos de diferenciação em que identidades e diferenças são formadas, como também refere Gilles Deleuze (1995). Uma identidade nunca é uma entidade fixa, unitária e acabada, mas sempre um processo de tornar-se uma identidade, em que certos grupos de significado são selecionados a partir de uma diversidade infinita de significados em potencial, em uma situação real. Esses conjuntos de significado não podem ser escolhidos sem a presença imanente desses outros significados potenciais que são deixados de fora. Essa presença imanente, no entanto, é imediatamente obliterada no processo de constituição de uma identidade e, ao mesmo tempo, está sempre lá, no fundo da identidade, como parte do plano, do ser (Deleuze, 1995).

Nós e eles, como relação de poder constitutiva do processo de construção de identidades que estamos examinando, remete, em muitos aspectos das falas dos jovens com quem trabalhamos, ao processo que o filósofo Sagot-Duvaroux (2006:23) chamou de "Um nós que falta", ao discutir os distúrbios de jovens nos subúrbios franceses em 2005. Com a frase ele buscava acentuar a dúvida que paira sobre a possibilidade de existência de uma identidade francesa coletiva e um "comum" a ser compartilhado por essa identidade. Em um tempo em que

Seu Cristo é judeu. Seu carro é japonês. Sua pizza é italiana. Sua democracia, grega. Seu café, brasileiro. Seu feriado, 
Vivências de jovens de periferia na França

turco. Seus algarismos, arábicos. Suas letras, latinas. Só o seu vizinho é estrangeiro (apud Bauman, 2005:33) ${ }^{16}$,

Sagot-Duvaroux insinua que essa identidade francesa não é o que une os franceses em uma comunidade de direito. Ela funcionaria, a seu ver, mais como uma prescrição latente contra todas as identidades - reivindicadas ou suspeitas. $\mathrm{E}$ as identidades juvenis das periferias das grandes cidades francesas $-e$, ao que parece, em todo o mundo - tem sido inscritas, crescentemente, nessas categorias.

Num sentido mais amplo "nós", para esses jovens cujas falas analisamos, pode ser estendido para os jovens do mesmo bairro, os jovens dos subúrbios e, em alguns casos, às pessoas que estão na mesma situação socioeconômica. De acordo com eles, o "nós" está vinculado a viver as mesmas experiências e espaço vital, ao falar a mesma língua $e$ ao compartilhar os mesmos valores $e$ códigos de conduta (as regras do bairro).

No pensamento de nossos interlocutores, "nós" é uma oposição a "eles". "Eles" são os do outro lado das fronteiras, grupos com quem os jovens não se identificam e pelos quais eles, também, não são reconhecidos como "nós". "Eles" não só seriam sempre diferentes de "nós", mas geralmente também hostis ao "nós". Quando os jovens falam sobre "eles", muitas vezes se referem a todos que estão associados com as instituições do Estado - políticos, juízes, policiais e, também, professores $e$ jornalistas. "Eles" pode, ainda, incluir aqueles que vivem em outras circunstâncias socioeconômicas, em bairros diferentes, pessoas que vivem no campo ou na capital, especialmente aqueles que vivem nos bairros mais ricos das grandes cidades.

Nessa interdependência de sentidos representados como excludentes, quanto mais se compartilha o mesmo tipo de experiência, mais se torna viável perceber-se como integrante de um certo estar-junto, uma determinada comunidade. As

${ }^{16}$ Texto veiculado como ironia em um cartaz, espalhado em Berlim, em 1994. 
experiências mais comuns são, exatamente, experiências de exclusão e de oposição ao domínio d "eles", como repressão policial, discriminação étnico-religiosa e dificuldades para encontrar um emprego. Essas experiências, negativas para os jovens, são compensadas por solidariedade, conectividade, valores partilhados e momentos alegres que a "comunidade de experiência" significa para eles. Vivenciando dificuldades semelhantes buscam encontrar um caminho comum para lidar com as diferenças e apoiar-se uns aos outros. Essa significação se expressa, no contexto deste trabalho, através do uso e da valorização de palavras como família, negócio, valores e regras do bairro.

Família são aquelas pessoas com quem você compartilha sua vida, que você respeita e que cuidam de você (Amina $\left.{ }^{17}\right)$. Os nossos pais vieram para a França para sair da miséria. Eles vieram para a França para melhorar suas vidas, caso contrário, teriam ficado no seu país, para cultivar batatas. Eles não querem que tenhamos as mesmas dificuldades que eles. Nossos pais ganharam o seu lugar, aqui, para nós. O que eles fizeram é muito honroso! Nossos pais tinham algo a provar, eles tinham que ganhar o seu lugar e nós reivindicamos os mesmos direitos que o outro francês, estamos no mesmo nível que o outro francês, mas os nossos pais não têm o mesmo nível (Ali).

Atacar a família é a coisa mais séria que pode acontecer, bater no meu pai é um motivo para um motim (Moussa).

Nossos pais têm mais respeito pela lei do que nós. Para eles, a polícia é do Estado e eles não querem ter problemas com o Estado. Nós pensamos de forma diferente sobre isso (Amina).

Além dos pais, amigos próximos também são uma parte fundamental da família. Os amigos que você considera

${ }^{17}$ Cumprindo um dos compromissos éticos que negociamos no processo de entrada no campo, todos os nomes são fictícios. 
Vivências de jovens de periferia na França

serem da família têm a mesma percepção do mundo, eles entendem as coisas da mesma maneira como você faz, eles compartilham a maioria de suas experiências de vida, eles passam pelo mesmo desenvolvimento que você faz $e$ compartilham o mesmo pensamento (Ali).

Para proteger amigos e parentes não devem existir limites, acreditam muitos de nossos interlocutores. Eles dizem que fariam qualquer coisa para ajudá-los, mesmo coisas que poderiam colocá-los em apuros diante de instituições de segurança estatais.

Família, nos excertos acima, extrapola tanto o sentido de família consangüínea quanto o de família nuclear moderna, sendo significada como um grupo ampliado em que redes de relações entre os membros, maior ou menor grau de cooperação, controle e cuidado, criam formas de proteção informal a ameaças, agressões e humilhações vindas de fora (d“eles"). Tal significação de família tem sido descrita, também, em contextos de periferias urbanas $e$ em grupos populares brasileiros $e$ foi, inclusive, incorporada às políticas públicas que visam promover a inclusão social (cf. Fonseca, 2000 e 2007; Barbosa e Cols, 2008).

Ao mesmo tempo, tem-se argumentado também (cf. Zaluar e Conceição, 2007) que áreas de grande precariedade, no Brasil com altos índices de desemprego e déficits habitacionais, educacionais, de saúde e de segurança, somados a intensos fluxos migratórios -, apresentariam baixa eficácia social em termos do estabelecimento de laços de confiança interpessoais e de redes de cooperação; e que isso acabaria por enfraquecer a capacidade de proteção das organizações familiares, ao mesmo tempo em que estimularia formas de individualismo em contraposição a formas solidárias.

Em Grigny, também em função de ser um território de imigrantes com composição étnico-religiosa muito semelhante entre si, foi possível observar que redes e laços sociais de solidariedade em famílias ampliadas estão mais presentes $e$, em muitos momentos, são mais valorizadas do que pertencimentos 
familiares e grupais estrito senso; ao mesmo tempo, e exatamente por essa significação, tais configurações são também móveis e provisórias, mudando em função do tipo de solidariedade $e$ proteção requeridos em determinada situação e contexto.

Segundo Claudia Fonseca (2007:22) "salta aos olhos a funcionalidade da rede extensa de parentes e conhecidos para os processos migratórios (...)", o que nos obriga a colocar sob suspeita a perspectiva eurocêntrica de uma relação "necessária entre modernidade e nuclearização da família". Nesse sentido, os agrupamentos derivados dessas "famílias em movimento" burlariam limites de vários tipos: entre o local, o nacional e o global e, ao mesmo tempo, em função de circunstâncias específicas, aqueles que envolvem relações de gênero e geração. Isso se expressa, por exemplo, na forma como "nossos pais" são posicionados: ora como alguém a ser honrado e protegido, ora como alguém que é diferente de "nós", na medida em que estabelece outro tipo de relações com a lei e o estado que ela representa ("nós pensamos diferente sobre isso").

Em alguns momentos, solidariedade e cooperação também foram significadas de formas diferenciadas entre os jovens homens $e$ as jovens mulheres. Para as participantes do grupo, essa regra de solidariedade não se impõe do mesmo modo e com a mesma força. Uma delas disse que "não faria coisas imprudentes ou ilegais para defender seus amigos sem uma longa e séria discussão (Amali)". Para os homens jovens, entretanto, a insubmissão diante das instituições vai sendo significada como um modo de existir com certa dignidade. Eles reivindicam ser tratados como franceses $e$ entendem como desonra e humilhação o fato de terem acesso apenas (quando tem) ao mesmo tipo de trabalho que seus pais estrangeiros tiveram quando chegaram à França. Essa indignação se expressa como elemento integrante de um certo ethos provedor, protetor e, ao mesmo tempo, justiceiro, em que a necessidade de vingança $e$ de reação imediata a qualquer ação/situação reconhecida como injustiça, se coloca como forma importante de obter (ou manter) respeito nos grupos de pertença. 
Vivências de jovens de periferia na França

Nesse caso, trata-se de uma sensibilidade justiceira desenvolvida de diferentes modos, seja através de longo aprendizado familiar e/ou, no caso dos homens jovens do grupo, no âmbito de um código de conduta denominado pelos jovens como a "lei do bairro".

Assim, ao mesmo tempo em que as jovens oscilam entre a posição de quem se alinha aos jovens quando dizem que pensam diferente de seus pais, elas se aproximam dos pais quando ponderam se coisas imprudentes ou ilegais valem o risco. Parece que para os jovens homens essas possibilidades "de escolha" não se colocam do mesmo modo nem nas normas familiares e nem nas "leis do bairro". Formas de viver como homem e como mulher vão se conformando em processos educativos múltiplos e, por vezes, conflitantes, que nunca estão finalizados, através de práticas sociais e institucionais e de estratégias que produzem, naturalizando, masculinidades e feminilidades.

$\mathrm{O}$ ethos justiceiro, como elemento constitutivo de identidades masculinas como a assumida pelos jovens de Grigny é, em grande parte, um aprendizado produzido tanto na relação com instituições sociais e estatais (especialmente a justiça, a polícia e a mídia), quanto na socialização das ruas onde crescem. ${ }^{18}$ Ao adotar, ou rebelar-se contra, seus códigos, eles procuram conquistar o respeito e a consideração dos membros da comunidade, bem como construir uma reputação que é importante para viver naquele contexto.

Especialmente a palavra justiça, vivenciada como injustiça, é muito significativa nesse processo de construção de identidade:

${ }^{18}$ Os jovens do grupo parecem, ao mesmo tempo, dar-se conta de quão danosa pode ser a lei do bairro, principalmente para a socialização das crianças, e decidiram desenvolver 3 projetos, a partir das reflexões feitas no grupo. Entre eles destacamos um atelier de escritura para crianças que denominaram de "Proteger as crianças da lei do Estado e da lei do bairro". 
Todos devem ser tratados igualmente, mas na verdade há uma grande desigualdade entre as pessoas. $\mathrm{E}$ isso é muito injusto (Adil).

E no trabalho, se você vem de Grigny, quando você tem os mesmos papéis que a pessoa a partir do $16^{\circ}$ arrondissement ${ }^{19}$ terá mais chance do que alguém que tem papéis de Grigny. Se alguém de Grigny colocar outro endereço, ele será contratado (Moussa).

Os promotores não fazem um esforço para realmente olhar para os detalhes de um processo; eles não conseguem olhar para o réu como um indivíduo (Moussa).

A administração da justiça é como o dono de um cão, e a polícia é o cão. O cão morde, mas o proprietário não. Com o proprietário você poderia ter uma conversa normal se você fosse considerado no mesmo nível humano. Do cão você só pode esperar que ele seja bem treinado pelo seu proprietário (Moussa).

Alguns jovens sustentam que o Estado é responsável pela criação de leis que aumentam ainda mais as desigualdades entre as pessoas. Muitos deles acham que jovens dos subúrbios não são tratados de forma igual perante a lei e que recebem punições maiores para a mesma infração do que outros jovens que vivem fora deles. A discussão sobre a gravidade de crimes diferentes, como roubo, furto e "crimes de colarinho branco", apareceu muitas vezes nas sessões do grupo. Eles argumentavam que pessoas da "elite" que cometem um ato criminoso - como empresários fraudulentos ou políticos corruptos - são menos punidos do que os jovens dos subúrbios. Em seu estudo, Kokoreff descreveu essas mesmas percepções que ele definiu como

sentimento de ser vítima de uma justiça de duas velocidades distintas, um sistema legal que tem duas

${ }^{19}$ Divisão territorial de Paris. O $16^{\circ}$ é um bairro cuja população possui condições socioeconômicas mais favoráveis. 
Vivências de jovens de periferia na França

engrenagens e que acelera mais rápido para condenar um jovem do subúrbio que um político fraudulento (Kokoreff, 2003:110).

Já para as mulheres jovens do grupo, as relações com a família, com os amigos e com as instituições parecem ser um pouco diferentes. Primeiro, a lei do bairro não parece se aplicar a elas do mesmo modo. Em função de valores étnicos, religiosos e morais, elas, como mulheres, precisam criar uma série de estratégias para estar no, ou para evitar o, espaço público do subúrbio, o mesmo onde os jovens homens, em grande medida, forjam suas masculinidades. Essas estratégias envolvem, por exemplo, sair acompanhadas ou até mesmo usar o véu ${ }^{20}$, e se elas querem namorar livremente precisam ir para longe do lugar onde moram.

Essa posição que impõe e permite às jovens mulheres que ouvimos expressar-se de outros modos deve-se à articulação de uma série de intrincados e complexos processos, como a menor pressão que elas sofrem da polícia, outros tipos de mobilidade social que lhes são demandadas e, ao mesmo tempo, uma forte vigilância dos homens com os quais convivem sobre seus comportamentos. Essa articulação, de certo modo, desloca o Estado e suas instituições do lugar de grande autoridade/ inimigo a ser vencido. $\mathrm{O}$ que se coloca para elas como possibilidade de liberdade, na maioria das vezes, significa exatamente sair do bairro e de sua rede de relações, assim que possível, ou casar.

Especialmente os significados relacionados à palavra polícia têm forte implicação na construção dessas masculinidades erigidas no espaço da rua, em contextos de periferias urbanas. Na opinião

${ }^{20}$ Para alguns estudiosos, o aumento da utilização do véu seria um retorno a um tipo de religiosidade e cuidado de preservação de valores culturais das famílias muçulmanas. No entanto, em decorrência de conversas privadas com algumas jovens pode-se afirmar que o uso do véu é, também, uma forma de serem respeitadas na comunidade e de evitarem ser importunadas ou alvo de brincadeiras de homens, que elas mesmas qualificam de machistas. 
de Moussa, a polícia se coloca acima da lei. A polícia é acusada de abuso de poder na maioria de suas intervenções, ou de não ajudar quando realmente deveria.

Uma conversa normal não é realmente possível com a polícia, porque eles olham só para o lado negativo. Para eles todos os jovens do bairro são suspeitos. Eles colocam todos no mesmo saco (Abdel).

Os jovens que saem na rua não são abordados de uma maneira pessoal, mas, em geral, tratados como delinqüentes em potencial (Moussa).

Eu chegava a ser revistado três vezes por dia, a caminho do futebol ou da escola para casa; isso é diário (Nabil).

As ações da polícia não têm qualquer legitimidade para nós (Moussa).

A presença constante da polícia e suas ações demonstram que a presunção de inocência não existe (Abdel).

É preciso levar em conta que, crescentemente, nos países ocidentais contemporâneos, incluindo o Brasil, tem-se investido, cada vez mais, no incremento de um aparato jurídico-policial que tem como foco a infância e a juventude, seja para a preservação de seus direitos, seja para a contenção e ressocialização daqueles que se desviam e que são reconhecidos como ameaça à ordem social estabelecida (Fonseca, 2004). Esse processo ganhou outras dimensões, na França, com a eleição de Sarkozy para a presidência. Portanto, a mudança política e institucional da natureza do Estado e do paradigma de segurança pública que nela se instaura não é simplesmente uma queixa dos jovens participantes. Trata-se de uma forma de governamento ${ }^{21}$ que permite criminalizar as periferias e aqueles que a habitam, em um processo em que castigo e punição passam a ser significados como um princípio político (cf. Thomassim, 2009).

${ }^{21}$ Termo utilizado e sugerido por Veiga Neto (2006:20), referenciando-se Foucault. 
Vivências de jovens de periferia na França

Nesse contexto, o "estrangeiro" é posicionado como alguém que quer tirar partido de benefícios sociais e/ou, quando árabe e/ou muçulmano, é relacionado com o terrorismo ou com a organização de violência urbana, nos casos de confronto com a polícia. Assim, jovens habitantes de periferias urbanas, trabalhadores sem documentos etc. são suspeitos a priori $e$ representados como inimigos da ordem pública e do bem comum.

Nessa gramática do risco à segurança pública, o Estado francês encoraja a polícia a questionar possíveis situações irregulares nas casas, a invadir apartamentos em busca de armas, a revistar transeuntes e a fazer buscas em carros suspeitos. Além disso, estabelece metas para prisões com premiações em dinheiro para policiais que alcançarem essas metas. Essa "vigilância armada" exercitada pelo governo toma trabalhadores, crianças $e$ jovens pobres e imigrantes como seu alvo e os trata como reféns (Bertho, 2006).

É claro que a forma como "a polícia" se relaciona com a população jovem masculina e vice-versa, na França contemporânea, faz parte de um processo de delimitação entre aqueles que seriam cidadãos de pleno direito - a identidade francesa que usufrui o direito de compartilhar o que é comum, conforme Sagot-Duvaroux (2006) - e os outros. Bauman descreve esses outros como "pessoas a quem se negou o direito de adotar a(s) identidade(s) de sua escolha", acrescidos daqueles que tem "negado o direito de reivindicar identidades distintas da classificação que lhes é atribuída e imposta" (2005:45-6) e que seriam aqueles recentemente denominados de "subclasse". Nessa posição, "qualquer outra identidade que você possa ambicionar ou lutar para obter lhe é negada à priori" ou, como expressa Moussa, você é "tratado como um delinqüente em potencial". É o medo do estranho, da diferença, daquilo que escapa ao que reconhecemos como "nós", que legitima a ação da polícia.

Essa perspectiva de segurança pública talvez subestime, justamente, a profundidade das desestabilizações sociais que ela produz. $\mathrm{E}$, no caso dos subúrbios franceses $e$, possivelmente 
também no caso das periferias urbanas brasileiras ${ }^{22}$, essa desestabilização pode estar associada a uma crescente disposição para reagir dos jovens. O que nos permite supor que um dos fatores implicados com o fracasso de muitas das ações de segurança pública contemporâneas seja, justamente, o clamor cada vez maior por "mais segurança". Esse contexto pode ser tomado, também, como potencializador de (nem tanto) novas formas de masculinidade - aquelas que assumem o que chamamos aqui de ethos justiceiro. Para Alba Zaluar:

(...) há importantes transformações sociais globais que atingem simultaneamente várias formações sociais $e$ subjetivas no mundo. Novas identidades e práticas masculinas vinculadas à dominação masculina e ao poder definido como característica viril foram surgindo $e$ se cristalizando em processos sociais já bem estudados. Nesse caso, não se trata da continuidade da família patriarcal, mas sim de uma sociedade em que toda autoridade tradicional está em crise, inclusive a dos pais, na qual o poder fragilizado vem a ser exercido com a exigência de uma submissão sem falhas e uma obediência incondicional dos(as) dominados(as) (Zaluar, 2009:22).

O ethos justiceiro convive, de forma conflituosa, com significações desencadeadas a partir das palavras respeito $e$ reputação, também muito enfatizadas entre esses jovens.

Quando se caminha nas ruas de Grigny em um dia ensolarado, podem-se ver as pessoas parando para cumprimentar umas às outras no meio de um cruzamento,

${ }^{22}$ É claro que é preciso considerar as especificidades das periferias européias e brasileiras contemporâneas, sobretudo, no que se refere às vivências do "ser imigrante" e "estrangeiro". Entretanto, vários componentes dessa problemática, referida pelos jovens, podem ser disparadores de reflexões importantes acerca da relação quase naturalizada que se estabelece entre juventude, masculinidade, pobreza e violência, também no Brasil. 
Vivências de jovens de periferia na França

apertando mãos e trocando cumprimentos. Nós ensinamos essas regras gerais de cortesia às crianças daqui, porque esta é a maneira como as coisas funcionam "entre nós" (Ali).

Eu não sei por que os jovens aqui são tão respeitosos. Talvez porque nós sejamos os mais antigos do bairro, eles são obrigados a se comportar, porque eles sabem muito bem... que não queremos agredi-los, mas nós também sabemos como e o que falar com eles, a linguagem que eles vão entender; e eles sabem que as palavras provenientes de nossas bocas são para ajudá-los. É a maneira de falar que importa (Moussa).

Esse comportamento partilhado, não só faz as pessoas se sentirem em casa, num certo nível básico de reconhecimento, mas também reflete valores que são comumente acolhidos por pessoas do bairro. Respeito e reputação não se traduzem apenas em regras de cortesia, mas são partes essenciais de uma atitude cotidiana.

Esses valores de cortesia e respeito frente à reputação denotam componentes constitutivos dessa masculinidade, e eles convivem com a sensibilidade justiceira, em suas dimensões de provisão e proteção, expressando-se através de ações de cavalheirismo e de cordialidade. Essas ações funcionam como formas visíveis de contraposição às representações de falta de civilidade e violência que marcam e discriminam populações periféricas e pobres (Cecchetto, 2004; Wacquant, 2008).

Regras de cortesia são cultivadas, ali, como valores fundamentais da convivência no bairro e são, ao mesmo tempo, valores que se diferenciam da convivência anônima nas grandes cidades. Essas regras, entretanto, estão também atreladas a noções de honra e de dignidade que, no limite, circunscrevem possibilidades profissionais dos jovens naquele contexto:

Porque tudo o que nos resta, é a honra e a dignidade. E às vezes alguns deles estão prontos para morrer por isso. Há muitas pessoas que se envolvem em formas muito graves 
de criminalidade, muito perigosas. Mas a vida continua. Não é o fim do mundo (Nabil).

Porque você não está trabalhando para um patrão $e$ seu sucesso nos negócios depende completamente dos valores que você honra. Se você não mantiver sua palavra, por exemplo, você perde a sua posição; assim você tem que manter seus padrões elevados em relação aos outros. Enquanto estiver "no comércio" você não tem um contrato com certas condições especiais, você tem um contrato baseado em princípios (Nourredine).

Apesar das dificuldades vividas em locais desfavorecidos como Grigny, as pessoas orgulham-se de ter dignidade. Quanto mais negativa se torna a imagem dos subúrbios, e lugares como Grigny são representados como "difíceis", "violentos" e "perigosos", mais seus habitantes acham importante Jamais baisser les brás (nunca desistir), como disse Nabil:

A solidariedade, a fraternidade, o espírito de equipe, o respeito, a dignidade. Mesmo quando alguém não tem nada, mas mantém uma dignidade, uma honra, isso é realmente importante, são esses os valores que realmente importam no bairro. Quando você vê como Fadela Amara ${ }^{23}$ tenta destruir a imagem dos jovens dos subúrbios, falando deles como sendo vulgares, animais, que somos violentos, $e$ que as meninas são estupradas, é terrível tudo isso (Nabil).

Nessa direção, a forma como a mídia aborda as tensões entre os jovens e a polícia é descrita por eles como altamente discriminadora. A TV estaria mostrando apenas imagens dos subúrbios que se encaixam em classificações já estabelecidas $e$ legitimadas - lugares "difíceis", "sensíveis", "violentos". A opinião

${ }^{23}$ Fadela Amara é a atual ministra de assuntos dos subúrbios. Apesar de ser originária dos subúrbios é considerada pelos jovens como uma traidora, pois, segundo eles, negou seu passado para conquistar o poder. 
Vivências de jovens de periferia na França

geral dos jovens é que a mídia só mostra o que interessa a "eles" mostrar.

Acho que eles generalizam demais. Quando se falam destes locais desfavorecidos generalizam demais. O povo reproduz o que falam os jornais, que o bairro é violento, que é ruim, eles falam o que eles vêem na mídia: que o bairro não presta e é violento. Para a imagem do bairro isso é muito ruim, pra gente que mora aqui é ruim, o bairro aqui é sinônimo de violência e pra gente que mora aqui é muito ruim (Michel).

Ao assistir TV você só vê os brancos nos comerciais, porque negros $e$ magrebianos não são considerados representativos. Os talentos de pessoas dos subúrbios permanecem despercebidos devido a esta tendência, embora haja tantos talentos para descobrir (Cédric).

Nesse sentido, o discurso midiático também está implicado com a produção dessas masculinidades juvenis, na medida em que são os jovens homens que aparecem mais nas imagens que constroem a relação entre subúrbio e violência. Segundo Pedro Pereira (2009:487):

A imprensa grava e ressalta determinadas dimensões de forma mais ou menos consciente [nós diríamos intencional]. Embora esses discursos se construam com base em representações coletivas, condensando emoções vivenciadas coletivamente nas imagens $e$ nas letras reproduzidas pela mídia, existe certo grau de consciência [intencionalidade] nos jornais que indica a dimensão ideológica. Os jornais não são apenas portadores de eficácia mágica que consolidam a reciprocidade entre editores e leitores; são discursos posicionados e valorados.

Em contextos representados como "difíceis", o princípio de nunca desistir (Jamais baisser les Brás) torna-se particularmente 
importante para homens jovens que aprendem que devem evitar, a qualquer custo, posições de subalternidade. O argumento de manter a dignidade pode, então, também ser aplicado para justificar a escolha de tornar-se ativo na economia clandestina do bairro. Eles (segundo dizem) desejariam participar da economia formal, como todos os outros, mas, diante das dificuldades para conseguir um emprego que se ajuste às suas expectativas, muitos deles preferem entrar no "negócio da droga" ou em outra atividade arriscada a ficar em uma posição subalterna - seja esta posição um trabalho onde eles têm que obedecer a um patrão, enquanto se ganha pouco dinheiro, ou uma situação em que se depende de bolsas ou auxílios de programas de serviço social. Isso, para eles, é representado como uma indignidade maior do que a de envolver-se em atividades designadas como ilegais, por um Estado no qual não se sentem acolhidos como membros legítimos. Ao mesmo tempo, ter acesso a uma renda ou a um salário que corresponda às suas expectativas está relacionado tanto com a capacidade de provisão articulada ao masculino, quanto ao desejo e à capacidade de consumo de artigos disponibilizados à juventude em contextos sociais urbanos de países de "primeiro mundo".

Dignidade e respeito, articulados à noção de reputação que os jovens buscam construir para si, enreda-se, em alguns momentos e situações, também com uma certa reputação de Grigny, como explica Said. Jovens como ele, e gangues relacionadas com essas atividades ilegais, por exemplo, positivam essa reputação e falam dela com orgulho.

Quando eu estava na cadeia na última vez foi como se todo mundo viesse de Grigny, você sabe. Eles todos diziam que vieram de Grigny quando alguém perguntava a eles. É porque todo mundo sabe que a vida em Grigny é dura, $e$ você tem que ser duro quando você vem de lá. Então, todos eles queriam ser conhecidos como homens de Grigny. Mas eu sou de Grigny e sei quem é do bairro, então eu sabia que todos eles estavam mentindo (Said). 
Vivências de jovens de periferia na França

$\mathrm{Na}$ medida em que a identidade filho de imigrantes africanos e/ou árabes se torna uma diferença que dificulta a esses jovens ver-se reconhecidos como jovem francês, ser de Grigny permite inventar para si uma identidade positiva - um homem duro de Grigny - na qual se articula de forma específica o que se vive $e$ se significa naquele contexto como família, honra $e$ reputação (dentre outras), em confronto e em disputa com o que se vivencia como justiça, polícia e mídia. Conjuntos de significações que se expressam como elementos fundamentais de processos de construção de identidades naquele territóriocomunidade.

Entretanto, esse também é um nós fraturado, na medida em que, ao mesmo tempo em que viver em um local representado como violento e degradado é significado como um importante capital cultural, como se pode ler nas palavras de Said; para outros, como Nabil, essas representações são terríveis. Assim, mais do que ressaltar e definir uma determinada masculinidade juvenil que estaria sendo aí produzida, é importante dar-se conta que elas assumem essas configurações - móveis, tensas e provisórias quando estão em interação, em um movimento que também está sempre aberto a novas, e outras, interconexões.

\section{...e porque é preciso terminar}

Nas falas que apresentamos e discutimos, descrevemos elementos imbricados em três dimensões importantes dos processos de diferenciação que produzem diferenças e identidades naquele contexto: a reputação, a força de caráter e a manutenção de uma rede relacional. Essas dimensões nos parecem fazer parte da maneira com que esses jovens homens se narram e, ao mesmo tempo, se apropriam dos espaços públicos aos quais tem acesso.

Sobre sua relação com o Estado francês, poderíamos dizer que as ações de segurança implementadas por ele para conter $e$ reduzir a ameaça que o subúrbio representa - revistas constantes, prisões, invasões de casas e prédios de particulares, desrespeito a 
pessoas mais velhas e práticas racistas - são traduzidas como ações que precisam ser respondidas por esses jovens. Se o direito à violência por parte do Estado está legitimado, porque não teriam o direito a se defender? É o que eles se perguntam para justificar o ethos justiceiro que assumem.

Assim, pode-se (e diríamos, deve-se) reconhecer que muitos dos elementos constitutivos dessas masculinidades juvenis se aproximam bastante daquelas masculinidades hegemônicas que temos confrontado no campo dos estudos de gênero. Ao mesmo tempo, talvez se deva também admitir que essas formas hegemônicas de masculinidade parecem, ainda, interessar aos "Estados" $e$ às sociedades das quais fazemos parte; $e$ isso tanto do ponto de vista de sua produtividade em termos de manutenção $e$ fortalecimento da ordem instituída, quanto da potencialidade de seu capital eleitoral, em contextos de importantes reconfigurações de processos econômicos, de trabalho e de direitos sociais.

Nesse sentido, assimetrias e desigualdades de gênero $e$ intra-gênero continuam, sim, muito presentes em todos os contextos sociais, algumas talvez mais fortes que outras, algumas mais presentes nas periferias e outras nos chamados "centros urbanos". Mas o fato dessas assimetrias não serem reconhecidas $e$ nomeadas pelos homens jovens com os quais conversamos não significa que o uso da força seja um elemento constitutivo, por natureza, destas identidades.

Muito provavelmente, isso está a indicar que ainda precisamos investir bastante na problematização $e$ na desconstrução de relações de poder de gênero naturalizadas $e$ socialmente sancionadas - que estão profundamente entranhadas em nossas vidas - ao mesmo tempo em que aponta e delineia um campo de possibilidades especialmente significativo para reflexão $e$ intervenção de educadoras e educadores. Pensar e agir nessa ótica pode contribuir para modificar, de forma importante, processos educativos que, sob a égide do argumento de "fortalecimento da auto-estima", por exemplo, continuam investindo em atributos como agressividade, competição, 
Vivências de jovens de periferia na França

provisão, proteção e honra como sendo atributos a serem, necessariamente, estimulados para os meninos $e$ jovens que educamos. Talvez essa seja uma das possibilidades de intervir na "violência nossa de cada dia": tanto aquela que sofremos, quanto aquela que ajudamos (mesmo sem perceber) a implementar e a manter.

\section{Referências bibliográficas}

ANDRADE, Sandra dos Santos. Juventudes e processos de escolarização: uma abordagem cultural. Tese de Doutorado em Educação, Universidade Federal do Rio Grande do Sul, 2008.

BARBOSA, Tais; BAndeIRA, Gustavo A.; MeYer, Dagmar. Conceitos de família operados em um programa de inclusão social no Brasil. Anais da IX Jornadas Nacionales de Historia de las Mujeres y IV Congreso Iberoamericano de Estudos de Género, Rosário-Argentina, vol. 1, 2008, pp.1-10.

BAUMAN, Zygmunt. Identidade. Rio de Janeiro, Jorge Zahar Ed., 2005. . Modernidade Líquida. Rio de Janeiro, Jorge Zahar Ed., 2001.

BERTHO, Alain. Bienvenue au 21e siècle! In: La Dispute: Banlieue, lendemains de révolte. Paris, La Dispute/Regards, 2006.

CECCHETTO, Fátima Regina. Violência e estilos de masculinidade. Rio de Janeiro, Ed. FGV, 2004.

DeleuZE, Gilles. Diferença e repetição. Rio de Janeiro, Ed. Graal, 1995.

FISCHER, Beatriz D. Foucault e histórias de vida: aproximações e que tais. História da Educação, vol. 1, n 1, ASPHE, abril de 1997, pp.5-20.

FISCHER, Rosa Maria Bueno. Foucault e a análise do discurso em educação. Cadernos de Pesquisa, vol. 114, 2001, pp.197-223.

FONSECA, Claudia. De família, reprodução e parentesco: algumas considerações. Cadernos Pagu (29), Núcleo de Estudos de GêneroPagu/Unicamp, jul-dez 2007, pp.9-35.

. Os direitos das crianças - Dialogando com o ECA. In: FONSECA, Claudia et alii. (orgs.) Antropologia, diversidade e direitos humanos. Diálogos interdisciplinares. Porto Alegre, Ed. da UFRGS, 2004, pp.103-16. 
. Família, fofoca e honra: etnografia de relações de gênero $e$ violência em grupos populares. Porto Alegre, Ed. da UFRGS, 2000.

FouCAULT, Michel. Ditos e escritos. vol. IV. Michel Foucault: Estratégia, Poder-Saber. Rio de Janeiro, Forense Universitária, 2006

- Arqueologia do saber. $3^{\mathrm{a} e d .}$ Rio de Janeiro, Forense Universitária, 1987.

Em defesa da sociedade. São Paulo, Martins Fontes, 1999.

GIBLIN, Béatrice. Dictionaire des Banlieus. Larousse, Paris, 2009.

GILES, Judy; MIDDLETON, Tim. Studying culture. A practical introduction. Oxford (UK), Blackwell Publishers, 1999.

HALL, Stuart. (ed.) Representation: cultural representations and signifying practices. London, Open University/Sage, 1997.

KOKOREFF, M. La force des quartiers; de la délinquance à l'engagement politique. Payot, Paris, 2003.

LAZARUS, Sylvain. Anthropologie du Nom. Editions du Seuil, Paris, 1996.

LOURO, Guacira. Currículo, gênero e sexualidade - o "normal", o "diferente" e o "excêntrico". In: LOURO, G.; NECKEL, J. F.; GOELLNER, S. V. (orgs.) Corpo, gênero e sexualidade: um debate contemporâneo

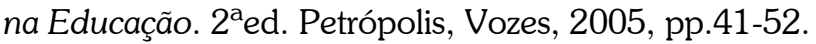

MEYER, Dagmar E.; SANTOS, Luís Henrique Sacchi dos; OliveIRA, Dora Lúcia de; WiLHEMS, Daniela Montano. "The shameless woman" and "the responsible cheater": analyzing gender representations in Public Service announcements for HIV/AIDS prevention. Revista Estudos Feministas, vol. 1, n², Florianópolis, 2006, pp.1-27.

MEYER, Dagmar E. E. Gênero e educação: teoria e política. In: LOURO, G.; NeCKEL, J.; GoELlner. S. (orgs.) $2^{\mathrm{a}}$ ed. Corpo, gênero e sexualidade: um debate contemporâneo na educação. Petrópolis, Vozes, 2005, pp.9-27.

. Dagmar. Teorias e políticas de gênero: fragmentos históricos e desafios atuais. Revista Brasileira de Enfermagem, vol. 1, $\mathrm{n}^{\circ} 1$, Rio de Janeiro, jan/mar., 2004, pp.13-18.

MUCCHIELLI, L. La police dans les 'quartiers sensibles': un profond malaise. In: MucChielli, L. \& LE GoAzIOU, V. (eds.) Quand les banlieues brûlent... Retour sur les émeutes de novembre 2005. Paris, La Découverte, 2008. 
Vivências de jovens de periferia na França

NICHOLSON, Linda. Interpretando o gênero. Revista Estudos Feministas, vol. 8, n 2, Florianópolis, 2000, pp.9-41.

PAIS, José Machado. Máscaras, jovens e "escolas diabo" Revista Brasileira de Educação, vol.13, n 37, jan/abr. 2008, pp.7-21.

Pereira, Pedro Paulo Gomes. Violência e tecnologias de gênero: tempo e espaço nos jornais. Revista Estudos Feministas, vol. 17, $\mathrm{n}^{\circ} 2$, Florianópolis, agosto de 2009, pp.485-505.

SAGOT-DUVAROUX, Jean Louis. Le 'nous' manquant. In: EDITIONS DE L'ECLAT. Banlieu, lendemain et révolte. Paris, La Dispute, 2006.

SHORE, Cris; WRIGHT, Susan. Anthropology of policy - Critical perspectives on governance and power. London, Routledge, 1997.

SiLVA, Tomaz T. O currículo como fetiche. A poética e a política do texto curricular. Belo Horizonte, Autêntica, 1999.

SPÓsITO, Marilia Pontes. Considerações em torno do conhecimento sobre juventude na área da educação. In: SPÓsITO, Marilia Pontes. (org.) Juventude e escolarização (1980-1998). Brasília, MEC/ Inep/Comped, 2002, pp.7-34.

. Estudos sobre juventude em educação. Revista Brasileira de Educação, nº 5/6, 1997, pp.37-52.

THOMASSIM, Luis Eduardo Cunha. Juventude, segurança e paz: "pra não dizer que não falei de esportes". In: ASQUIDAMINI, Fabiane. (org.) Contratempos: Juventude, segurança e paz. $1^{\mathrm{a} e d}$. São Leopoldo, CEBI (Centro de Estudos Bíblicos), 2009, pp.84-94.

VeigA-Neto, Alfredo. Dominação, violência, poder e educação escolar em tempos de Império. In: RAGO, Margareth; VeIGA-NETO, A. (orgs.) Figuras de Foucault. Belo Horizonte, Autêntica, 2006, pp.13-38.

WACQUANT, Löic. Urban Outcasts; A comparative sociology of advanced marginality. Cambridge, Polity, 2009.

ZALUAR, Alba. Agressão física e gênero na cidade do Rio de Janeiro. Revista Brasileira de Ciências Sociais, vol. 24, 2009, pp.9-24 [http://www.scielo.br/scielo].

e CONCEIÇÃO, Isabel S. Favelas sob o controle das "Milícias" no Rio de Janeiro: que paz?. São Paulo em Perspectiva, 21(2), jul./dez. 2007, pp.89-101. 